\title{
Modelling fabric development along the GRIP ice core, central Greenland
}

\author{
O. Castelnau, \\ Laboratoire de Glaciologie et Géophysique de l'Environnement, 38402 Saint-Martin-d'Hères Cedex, France \\ Th. Thorsteinsson, J. Kipfstuhl, \\ Alfred-Wegener-Institut für Polar- und Meeresforschung, Postfach 120261, D-27515 Bremerhaven, Germany \\ P. Duval, \\ Laboratoire de Glaciologie et Géophysique de l'Environnement, 38402 Saint-Martin-d'Hères Cedex, France \\ G. R. Canova \\ Laboratoire de Génie Physique et Mécanique des Matériaux, 38402 Saint-Martin-d'Hères Cedex, France
}

\begin{abstract}
The preferred $c$-axes orientation (fabric) observed in cold polar ice is induced by intracrystalline slip only when the grain-boundary migration rate is low enough (i.e. corresponding to grain growth or rotation recrystallization regimes). Fabrics reflect the entire thermomechanical history of the ice and strongly influence its mechanical behaviour. Large viscoplastic anisotropy is always associated with pronounced fabrics. We use a viscoplastic self-consistent (VPSC) polycrystal deformation model to calculate fabric development. In this model, stress- and strain-rate fields are not uniform within the polycrystal and both equilibrium and compatibility conditions are fulfilled. We compare fabrics measured on thin sections along the GRIP ice core (central Greenland) with those calculated down to a depth of $2800 \mathrm{~m}$. Behaviours predicted by uniform stress and uniform strain bounds are presented for comparison. Predictions of the VPSC model are in close agreement with measurements within the upper $650 \mathrm{~m}$, which corresponds to the entire grain-growth zone. Deeper down, the simulated fabric strength appears to be too high. A simple calculation shows that this discrepancy may be fully attributed to the effects of rotation recrystallization.
\end{abstract}

\section{INTRODUCTION}

Studies of several deep ice cores have revealed the development of highly preferred $c$-axes orientations Gow and Williamson, 1976; Herron and others, 1985; Lipenkov and others, 1989). A detailed study of the textures and fabrics in the GRIP ice core, drilled at Summit (central Greenland) during the years 1989-92, was described in detail by Thorsteinsson and others (1995, in press). An outline of the evolution of these parameters in the interval $100-2800 \mathrm{~m}$ is presented in this paper (section 3).

Fabrics generally reflect the entire deformation history of ice particles, from their deposition at the ice-sheet surface down to their present depth (Duval and Castelnau, 1995). Polar ice displays an increasing viscoplastic anisotropy as the fabric develops. A large strain-rate variation with the direction of the applied stress has been observed in both laboratory and in-situ measurements (Russell-Head and Budd, 1979; Duval and
Le Gac, 1982; Gundestrup and Hansen, 1984; Shoji and Langway, 1988; Budd and Jacka, 1989). This property renders the isotropic Norton-Hoff constitutive relation (the "Glen law") inadequate for modelling large-scale ice flow in cold ice sheets. Polycrystal anisotropy may introduce flow instability and could be the cause of the disturbed stratigraphy observed below $2850 \mathrm{~m}$ depth in the GRIP core. Lliboutry (1993) has proposed an anisotropic constitutive relation for polar ice, where the rheological parameters are determined from the polycrystal fabric. However, since fabrics develop with strain, these parameters must also change as the ice deforms. A more general description of the mechanical behaviour is given by physically based polycrystal deformation models, which relate the deformation of individual grains to that of the whole polycrystal. The aim of this paper is to compare fabric development simulated with such an approach with that measured along the GRIP ice core.

Intracrystalline dislocation glide is the dominant deformation mode for polycrystalline ice (Pimienta and 
Duval, 1989). Ice crystals display an extreme viscoplastic anisotropy, with only two independent easy-glide directions (basal glide). The contribution to the total deformation of other slip systems such as climb of basal dislocations on prismatic planes or non-basal dislocation glide is not significant (Duval and others, 1983; Fukuda and others, 1987). Within a polycrystal, the deformation of grains must be compatible, i.e. the formation of gaps between adjacent grains and an overlap of two adjacent crystallographic lattices is not possible. In the case of hexagonal crystals, Hutchinson (1977) has shown that only four independent slip systems per grain are sufficient. Due to the low number of easy-slip systems in ice crystals, a non-uniform stress state develops within polycrystals as deformation proceeds and load is transferred to grains poorly oriented for deformation by basal glide. As a result, the strain rate decreases by several orders of magnitude during the primary creep of polycrystals (Jacka, 1984). In polar ice, grain-boundary migration associated with dynamic recrystallization always occurs. According to Lliboutry and Duval (1985), this migration can relieve incompatibilities at grain boundaries (GB). A lower level of internal stress is then expected.

Three regimes of dynamic recrystallization are distinguished in polar ice (Pimienta and Duval, 1989; Alley, 1992; Duval and Castelnau, 1995): (i) Grain growth, driven by the surface energy of GB. Here, smaller grains are consumed by larger ones and the average crystal size increases linearly with time. This regime is observed generally in the upper few hundred metres of the large polar ice sheets. Since there is no correlation between grain-size and crystallographic orientation, this mechanism can influence fabric development only by relaxing the internal stress field (Castelnau and others, in press). (ii) Rotation recrystallization (polygonization). This results in the progressive misorientation of sub-boundaries, due to heterogeneous deformation within grains. GB migrate slowly, with a velocity slightly higher than that observed in the grain growth regime. The migration is driven by both GB energy and stored strain energy. According to Alley and others (1995a), the polygonization process counteracts further grain-size increase due to grain growth below $400 \mathrm{~m}$ depth in the Byrd Station core (Antarctica). In simple shear deformation, this process may stabilize the single-maximum fabric usually observed, where the $c$ axes are normal to the macroscopic shear plane (Duval and Castelnau, 1995). (iii) Migration recrystallization, resulting from the nucleation of grains by $\mathrm{GB}$ bulging and the rapid migration of GB. The fabric then reflects the instantaneous stress configuration. The strain corresponding to a wave of recrystallization is around 0.07 (Steinemann, 1954). This regime only occurs above a critical temperature of about $-12^{\circ} \mathrm{C}$.

The aim of polycrystal deformation models is to link the microscopic with the macroscopic state, i.e. stress and strain rate at the grain and polycrystal scales, respectively. Such models have been developed in glaciology (Azuma and Higashi, 1985; Fujita and others, 1987; Alley, 1988; Lipenkov and others, 1989; Azuma, 1995) but only for uniaxial and biaxial stress states. It is not evident how this kind of model can be generalized to an arbitrary stress state.

A static model (Sachs, 1928) has recently been applied to polar ice (Van der Veen and Whillans, 1994; Castelnau and Duval, 1994). This model, which assumes a uniform stress state (i.e. each crystal is subjected to the same stress), fulfils the stress-equilibrium condition across GB. However, since only the softest slip systems are active, the deformation of adjacent grains is incompatible. The other difficulty inherent in this model, which provides a lower bound for the stress, is that the rate of basal glide in each grain is adjusted to reproduce the mechanical response of an isotropic polycrystal. Consequently, this parameter depends on the fabric (Lliboutry and Duval, 1985 ).

Another simple theory was proposed by Taylor (1938), in which the strain is assumed to be uniform (i.e. each crystal is subjected to the same strain). This model leads to an upper bound for the stress and is not well suited for highly anisotropic materials. Indeed, five independent slip systems are required to produce any arbitrary imposed strain rate, since the strain-rate tensor possesses five independent components (ice being assumed to be incompressible). Furthermore, the equilibrium condition across the GB is violated. Applications to geological materials have been given by Wenk and others (1986, 1989b). Real polycrystal behaviour necessarily lies between static and Taylor estimations.

A more reasonable estimate of the macroscopic behaviour can be obtained with the viscoplastic selfconsistent (VPSC) theory developed by Hutchinson (1976) and formulated in a general way for the large deformation of anisotropic materials by Molinari and others (1987). Within the formulation of Molinari and others, the stress- and strain-rate fields are calculated in the polycrystal by solving stress equilibrium and incompressibility equations. The form of the non-linear constitutive relation of the polycrystal is not explicitly known. It is approximated by its tangent behaviour in the neighbourhood of the applied stress on the polycrystal surface. The whole polycrystal volume is discretized into small volume elements, in which the stress state is uniform. In its simplest form, the VPSC model consists of regarding each grain of the polycrystal as an inclusion embedded in an infinite homogeneous medium, which behaviour represents that of the polycrystal. This approximated solution has also been presented by Lebensohn and Tomé (1993) for anisotropic materials and will be used in the present work. This approach, briefly presented in section 2 , predicts an intermediate solution between uniform stress and uniform strain bounds. Applications to rocks and metals have been given by Wenk and others (1989a), Tomé and others (1991) and Lebensohn and Tomé (1994). The first application to ice polycrystals was presented by Castelnau and others (in press).

The GRIP ice core was drilled exactly at the actual crest of the Greenland ice sheet. At this location, shear deformation is not expected to be significant in comparison with axial deformation, at least in the upper half of the core. This situation leads to reliable estimates of the total deformation of the ice with depth. The data gathered from the GRIP core thus offer a unique possibility to test polycrystal models. In this paper, we compare the fabric development observed along the GRIP ice core for the depth range $0-2800 \mathrm{~m}$ using that 
calculated with the VPSC model of Lebensohn and Tomé (1993). Limit behaviours given by lower- and upperbound models are also presented for comparison. The validity of the model, as well as the effects of recrystallization processes, will be discussed.

\section{DESGRIPTION OF POLYGRYSTAL MODELS}

In this section, we present the main equations of the polycrystal deformation models used in this work (equations are expressed here using the Einstein summation convention on repeated indices). The reader will find more details about general VPSC formulation in Hutchinson (1976), Molinari and others (1987), and about the VPSC model we use in this work in Lebensohn and Tomé (1993). A general assumption of these models is that crystals deform by dislocation glide only and dynamic recrystallization processes are not taken into account.

At the grain level, the resolved shear stress on the slip system $s$ is given by

$$
\tau_{\mathrm{r}}^{s}=r_{i j}^{s} \cdot s_{i j}
$$

where $\underline{\mathbf{s}}$ denotes the microscopic deviatoric Cauchy stress tensor. The Schmid tensor $\underline{\mathbf{r}}^{s}$ expresses the orientation of the slip system $s$ relative to the reference frame in which $\underline{\mathbf{s}}$ is calculated so that

$$
r_{i j}^{s}=\frac{b_{i}^{s} n_{j}^{s}+b_{j}^{s} n_{i}^{s}}{2}
$$

where $\mathbf{n}^{s}$ and $\mathbf{b}^{s}$ are, respectively, unit vectors parallel to the slip-plane normal and to the slip direction associated with the system $s$. The shear rate $\dot{\gamma}^{s}$ on the system $s$ is given by the following power law:

$$
\dot{\gamma}^{s}=\dot{\gamma}_{0}\left|\frac{\tau_{\mathrm{r}}^{s}}{\tau_{0}^{s}}\right|^{n^{s}-1} \frac{\tau_{\mathrm{r}}^{s}}{\tau_{0}^{s}}
$$

where $\dot{\gamma}_{0}$ is a reference shear rate, and $n^{s}$ and $\tau_{0}{ }^{s}$ denote, respectively, the stress sensitivity and the reference resolved shear stress (RRSS) of the system $s$. Finally, the strain rate $\underline{\mathbf{d}}$ at the crystal scale is given by a summation over all $S$ slip systems, hence

$$
d_{i j}=\sum_{s=1}^{S} \dot{\gamma}^{s} r_{i j}^{s} .
$$

We call $\underline{\overline{\mathbf{S}}}$ and $\underline{\overline{\mathbf{D}}}$ the deviatoric Cauchy stress and strainrate tensors, respectively, applied uniformly on the polycrystal surface. The aim of polycrystal deformation models is to evaluate the microscopic state within a polycrystalline aggregate. The volume average (denoted $\langle\cdots\rangle)$ of microscopic stress and strain rate must be equal to the corresponding macroscopic quantities

$$
\left\langle s_{i j}\right\rangle=\bar{S}_{i j}
$$

and

$$
\left\langle d_{i j}\right\rangle=\bar{D}_{i j}
$$

Thus, a relation linking microscopic and macroscopic states must be introduced. This micro-macro relation completely determines the response of the polycrystal.

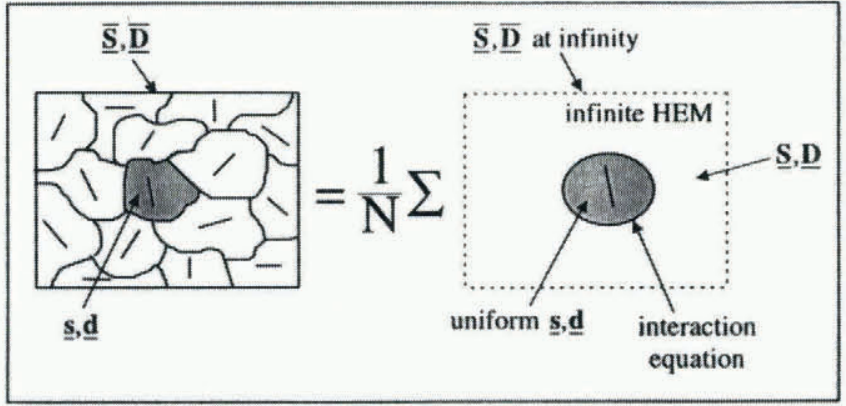

Fig. 1. Calculation scheme of the VPSC model: each grain is considered as an inclusion in a homogeneous equivalent medium, whose mechanical behaviour is that of the polycrystal.

The calculation principle of the VPSC model, which lies between static $\left(s_{i j}=\bar{S}_{i j}\right)$ and Taylor $\left(d_{i j}=\bar{D}_{i j}\right)$ limits, is schematically presented in Figure 1: each grain of the polycrystal is replaced by an ellipsoidal inclusion embedded in an infinite homogeneous equivalent medium (HEM), whose behaviour is equivalent to that of the whole polycrystal. The constitutive relation of the HEM is a result of the calculation and is given in the neighbourhood of $\underline{\overline{\mathbf{S}}}$ by the first-order Taylor expansion of the non-linear constitutive relation of the polycrystal (which is not known). It takes the following pseudo-linear form, which is frame-indifferent:

$$
D_{i j}=M_{i j k l}^{(\mathrm{tg})}(\underline{\overline{\mathbf{S}}}) \cdot S_{k l}+D_{i j}^{0}(\underline{\overline{\mathbf{S}}}) .
$$

$\underline{\mathbf{S}}, \underline{\mathbf{S}}, \underline{\overline{\mathrm{D}}}$ and $\underline{\mathrm{D}}$ define here deviatoric stress and strain rates, respectively, at infinity and within the HEM. $\underline{\underline{M}}^{(t g)}$ is the fourth-rank tangent compliance tensor, which

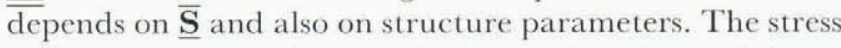
and strain rate within the inclusion (i.e. the grain) are assumed to be uniform. The so-called "one-site" approximation has been used by Lebensohn and Tomé (1993), i.e. the calculation of stress and strain rate of a grain does not take into account the influence of neighbouring grains. Consequently, only the interaction between the grain and the HEM is considered. This treatment leads to an interaction equation that linearly relates stress and strain rate in each grain with those on the polycrystal surfaces (Eshelby, 1957; Hill, 1965; Lebensohn and Tomé, 1993) so that

$$
d_{i j}-\bar{D}_{i j}=-\tilde{M}_{i j k l}\left(s_{k l}-\bar{S}_{k l}\right)
$$

The interaction tensor $\underline{\tilde{M}}$ can be expressed as a homogeneous function of degree 1 in $\underline{\mathbf{M}}^{(\mathrm{tg})}$ and depends on the shape of the inclusion. In the VPSC model of Lebensohn and Tomé, the macroscopic compliance and the interaction tensor are fully determined. This allows the HEM to have any anisotropic response.

Once convergence is achieved, the rotation rate $\underline{\mathbf{w}}^{\mathrm{c}}$ of crystallographic axes, which determines the fabric evolution, is calculated for each grain. It is given by the difference between the rotation rate of the HEM in the neighbourhood of the considered grain and the rotation rate of the grain itself. When the macroscopic rotation is 
null, it is expressed as

$$
w_{i j}^{\mathrm{c}}=w_{i j}^{\mathrm{e}}-w_{i j}^{\mathrm{p}}
$$

for the VPSC model. The microscopic plastic rotation rate $\underline{\mathbf{w}}^{\mathrm{p}}$ depends on all shear rates $\dot{\gamma}^{\mathrm{s}}$ in a grain and on the orientation vectors $\mathbf{n}^{s}$ and $\mathbf{b}^{s}$. The rotation rate $\underline{\mathbf{w}}^{\mathrm{e}}$ of the ellipsoid depends on the strain-rate deviation $\left(d_{i j}-\bar{D}_{i j}\right)$, on the grain shape and on the macroscopic compliance $\underline{\mathbf{M}}^{(\mathrm{tg})}$. Within the Taylor model, $\underline{\mathbf{w}}^{\mathrm{e}}$ vanishes, and $\overline{\text { Equation }}(9)$ gives

$$
w_{i j}^{\mathrm{c}}=-w_{i j}^{\mathrm{p}} .
$$

This relation is also used within the static model. It implies that the rotation of the neighbourhood of each grain (the local rotation) is null. Thus, the static model is incoherent, since rotations are completely constrained, and deformations completely free.

In this study, grain shape is not updated during the deformation (i.e. grains remain spherical). This parameter is not found to have a significant influence on fabric development along the GRIP core. Ice crystals are assumed to deform by dislocation glide on basal $\{0001\}\langle 11 \overline{2} 0\rangle$, prismatic $\{01 \overline{1} 0\}\langle 2 \overline{11} 0\rangle$ and pyramidal $\{11 \overline{2} 2\}\langle 11 \overline{23}\rangle$ slip systems. A stress exponent $n^{s}=3$ is taken for all systems. In ice sheets, the stress exponent $n$ of polycrystalline ice lies between 1 and 3 (Lliboutry and Duval, 1985). However, it has been verified that the value of $n$ has little influence on the results presented here. The RRSS for basal, prismatic and pyramidal slip was tuned in order to reproduce, with the VPSC model, the mechanical behaviour of both a monocrystal and an isotropic polycrystal (Castelnau and others, in press) so that

$$
\tau_{0}{ }^{\text {basal }}=\frac{\tau_{0}^{\text {prismatic }}}{20}=\frac{\tau_{0}^{\text {pyramidal }}}{200} .
$$

A very large resistance is then attributed to non-basal systems. Under these conditions, the contribution of basal slip to the total deformation is more than $90 \%$ with the VPSC model and more than $99 \%$ with the static model. However, it represents only $40 \%$ with the Taylor model, i.e. the remaining $60 \%$ are due to prismatic and pyramidal slip. This estimation is not satisfactory since a very low density of non-basal dislocations is observed in ice crystals (Fukuda and others, 1987). On the other hand, for conditions leading to $n=3$, the strain rate of an isotropic polycrystal calculated with the static model is two orders of magnitude larger than that determined experimentally for the same stress. Thus, static and Taylor models cannot be used for realistic modelling of polycrystalline ice behaviour.

\section{EVOLUTION OF TEXTURES AND FABRICS IN THE GRIP CORE}

Figure 2 presents an outline of the evolution of textures and fabrics (for more details, see Thorsteinsson and others, 1995, in press), together with the strain history (Dahl-Jensen and others, 1993; personal communication from S.J. Johnsen), temperature profile (Johnsen and others, 1995) and estimated time-scale (Dansgaard and others, 1993).

The schematic grain-size profile is shown in Figure 2a. Between 100 and $650 \mathrm{~m}$, average crystal size increases linearly with time in the regime of normal grain growth. Below $650 \mathrm{~m}$, no further increase in grain-size is observed. The entire interval $650-2800 \mathrm{~m}$ appears to be affected by the subdivision of crystals due to rotation recrystallization. This process likely causes the halt in grain growth at $650 \mathrm{~m}$ depth. The transition from Holocene ice to Wisconsin glacial ice is encountered at $1625 \mathrm{~m}$ depth and grain-size decreases as the ice age is entered. This can probably be attributed to the effects of soluble impurities, which are believed to impede GB migration if present in sufficiently high concentrations (Alley and others 1986; Paterson, 1991). The GR IP data show an anti-correlation between grain-size and soluble impurity concentration, particularly in the lower Wisconsin and "Eemian" ice below $2800 \mathrm{~m}$ (Thorsteinsson and others, 1995, in press). Below $2600 \mathrm{~m}$, grain-size starts increasing again, probably due to the higher ice temperature. Coarse-grained ice is found in the "Eemian" and "Pre-Eemian" ice below $2800 \mathrm{~m}$. There is clear indication that migration recrystallization is associated with this texture. The relatively high temperature in this zone $\left(>-15^{\circ} \mathrm{C}\right)$ is compatible with this recrystallization regime. The fabric of deep ice, between $2800 \mathrm{~m}$ and $3028 \mathrm{~m}$ (bedrock), has probably been affected by this rapid recrystallization process and is thus not considered in this study.

The measurements of $c$-axis orientation (Fig. 2b) have revealed a steady fabric development in the core, from random orientation at the surface to a strongly preferred orientation in the deeper parts. A vertical single maximum has formed at $2200 \mathrm{~m}$ and persists down to $2800 \mathrm{~m}$ depth. No sharp contrast in the fabric strength is observed across the Holocene-Wisconsin climatic transition. The steady evolution of the fabric is compatible with the ice-divide location of the Summit drill site, where the ice movement is mainly vertically downwards and hardly any horizontal movement has been recorded (personal communication from N.S. Gundestrup). Since Summit is located at the top of a dome, ice probably deforms by vertical uniaxial compression. The circular shape of the GRIP fabrics is compatible with this deformation state (Alley, 1988).

The time-scale for the GRIP core (Fig. 2e) relies on annual-layer counting in the Holocene ice and flow modelling deeper down (Dansgaard and others, 1993) using a simple Dansgaard-Johnsen type flow model (Dansgaard and Johnsen, 1969). The parameters of this model were determined such that the resulting time-scale matches the age of dated reference horizons down to $1625 \mathrm{~m}$ depth. This model assumes steady ice surface and steady bedrock (horizontal, constant elevation). The present accumulation rate $\left(0.23\right.$ m ice equivalent year $\left.{ }^{-1}\right)$ represents the mean annual accumulation rate during the whole Holocene period. The vertical deformation rate is supposed to be constant (with depth) from the surface down to a depth of $1750 \mathrm{~m}$ (Dahl-Jensen and others, 1993 . Deeper down, the vertical strain rate is assumed to decrease linearly with depth, reaching a zero value at the bedrock. Total thinning of annual layers from their initial 


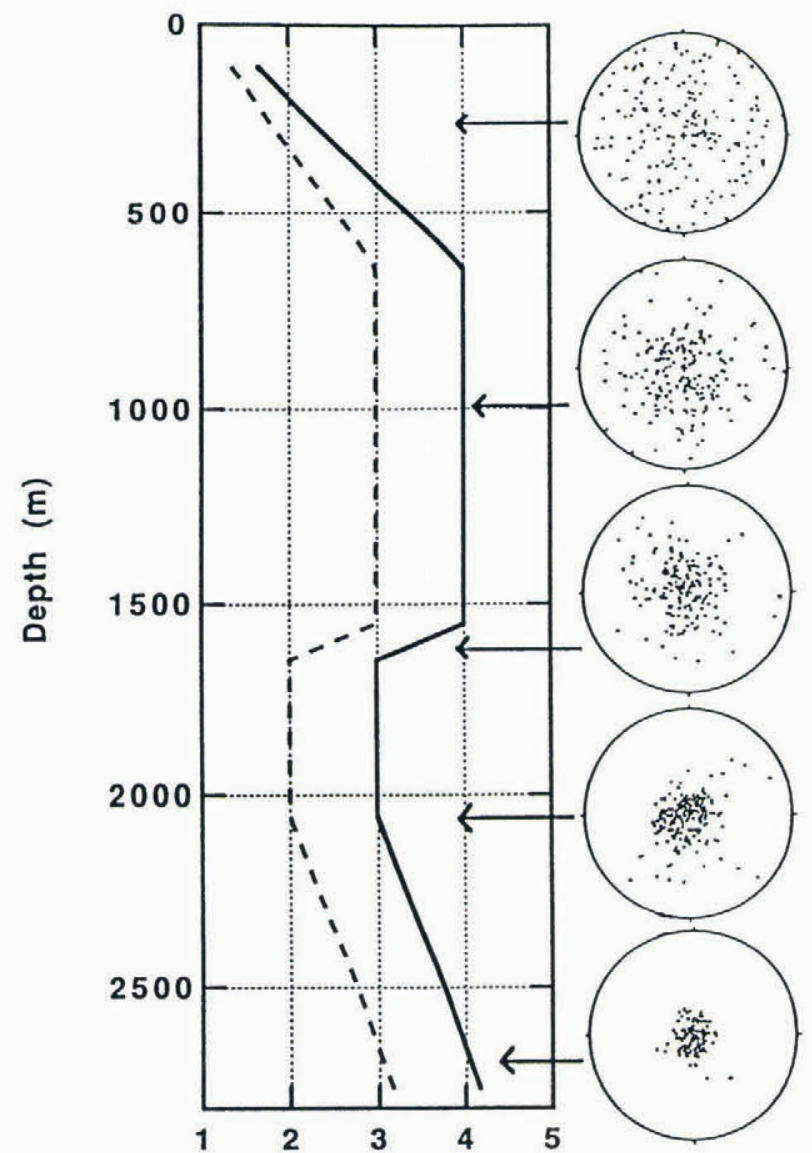

(a) Grain-size (b) Fabrics

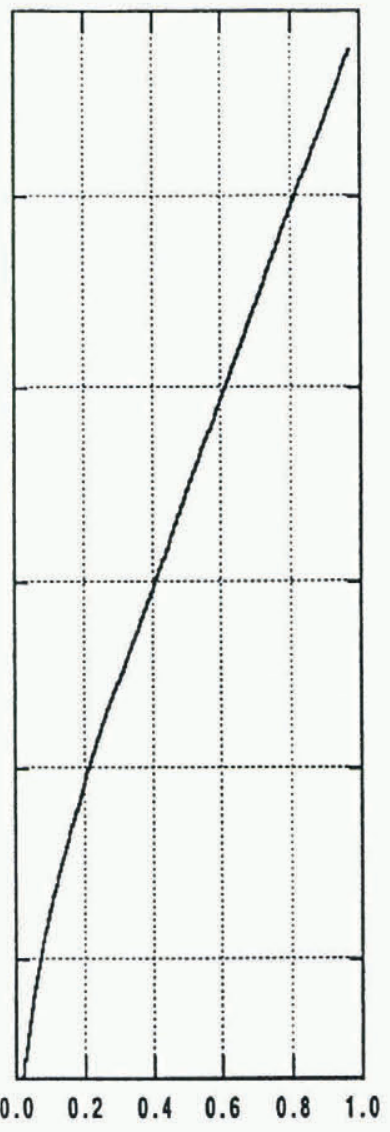

(c) $\mathbf{a} / \mathbf{a}_{0}$

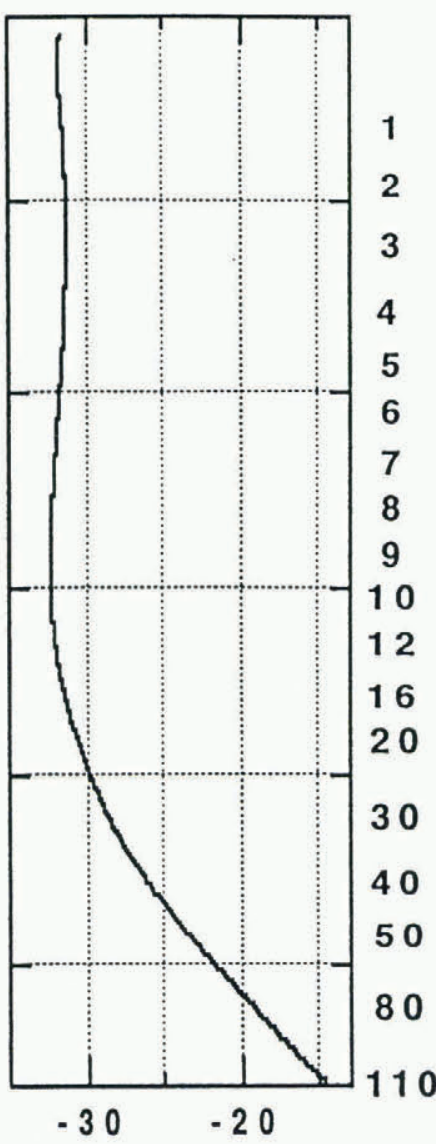

(d) $\mathrm{T}\left({ }^{\circ} \mathrm{C}\right)$ (e) Age (kyear)

Fig. 2. (a) Schematic grain-size profiles from the GRIP core. The full curve shows average horizontal crystal diameters, the dashed curve vertical diameters (Thorsteinsson and others, 1995b). (b) Selected c-axis fabric diagrams from five different depths in the GRIP core: 249.2, 991.1, 1625.8, 2064.2 and $2696.1 \mathrm{~m}$. The centre of the diagrams indicates the insitu vertical direction (Thorsteinsson and others, 1995b). (c) Ratio a $/ a_{0}$ of the present thickness of the annual layer in the ice sheet to the original thickness of the same layer during its deposition at the surface (Dahl-Jensen and others, 1993; personal communication from S. F. Johnsen). (d) Temperature profile in the GRIP borehole (Johnsen and others, 1995). (e) Estimated time-scale (Dansgaard and others, 1993).

thickness (at the surface) to their present thickness (deep in the ice sheet) has also been derived by this flow model. The profile of the annual-layer thickness ratio $a / a_{0}$ is presented in Figure 2c. These data yield the cumulative vertical strain $\varepsilon_{z z}$ (deformation gradient) which the ice has been subjected to along the ice core and

$$
\frac{a}{a_{0}}=1+\varepsilon_{z z} \text {. }
$$

These results indicate that the GRIP ice has experienced considerable vertical compression: 0.25 at $650 \mathrm{~m}, 0.64$ at $1625 \mathrm{~m}$ and more than 0.9 below $2400 \mathrm{~m}$ depth.

Ice temperature (Fig. 2d) does not deviate more than $0.5^{\circ} \mathrm{C}$ from the present mean annual surface temperature $\left(-32^{\circ} \mathrm{C}\right)$ in the uppermost $1800 \mathrm{~m}$ of the drillhole. Below this depth, the temperature increases steadily to $-15^{\circ} \mathrm{C}$ at $2800 \mathrm{~m}$, and reaches $-9^{\circ} \mathrm{C}$ at the bottom of the hole.

\section{RESULTS AND DISCUSSION}

Fabric development along the GRIP core was simulated with the VPSC model. Results will also be compared to those obtained with static and Taylor models. The initial polycrystal, which is an input for the models, is randomly oriented and contains 200 grains. The imposed deformation is a vertical uniaxial compression. The polycrystal models relate the fabric pattern to the vertical deformation $\varepsilon_{z z}$. The depth corresponding to the simulated fabrics is calculated using the estimation of the annuallayer thickness ratio $a / a_{0}$ (Fig. 2c).

Figure 3 shows the GRIP $c$-axis fabric observed at $991.1 \mathrm{~m}$ depth, compared to that found with static, VPSC and Taylor polycrystal models for a vertical deformation of 0.387 , corresponding to about the same depth $(990 \mathrm{~m})$. We found that the general GRIP fabric pattern can be reproduced numerically. $c$ axes rotate towards the principal direction of compression, i.e. towards the in-situ vertical direction. With the static model, the fabric pattern shows a small circular girdle. However, the distribution of $c$ axes around the vertical predicted with each model appears to be very different. A very pronounced fabric is found with the static model and a much more open one with the Taylor model. The selfconsistent estimate gives an intermediate result, close to that of the static model. At a depth of $990 \mathrm{~m}$, the 


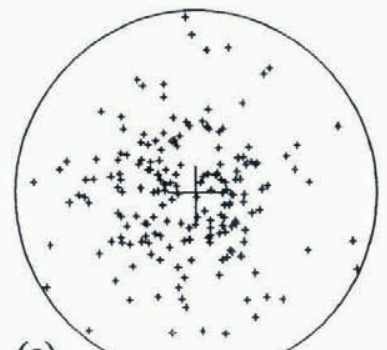

(a)
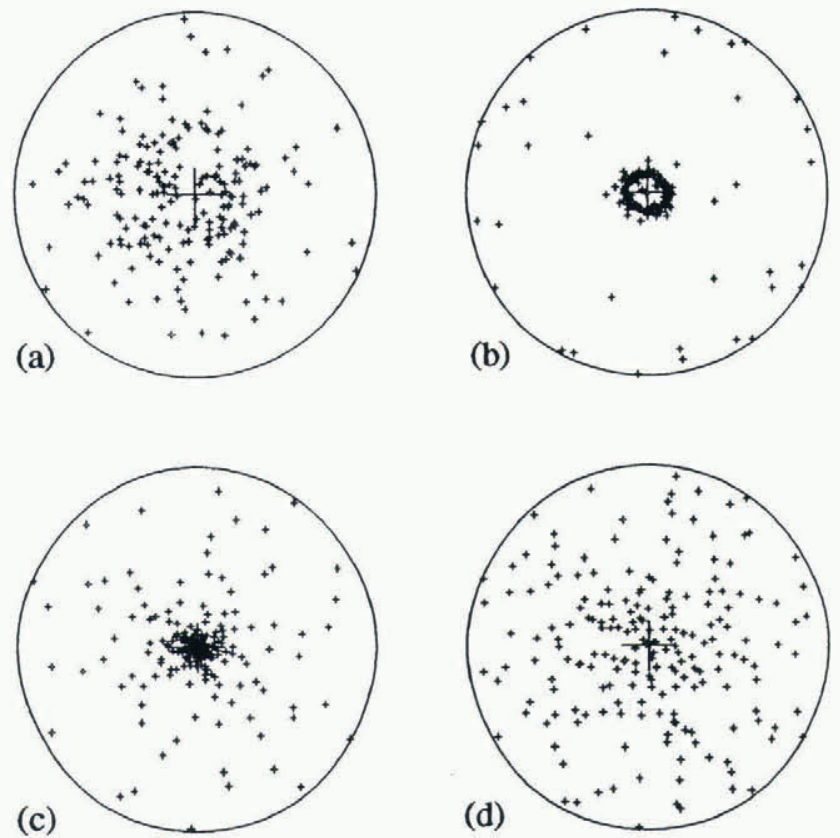

Fig. 3. Comparison of (a) the fabric pattern of the GRIP ice for a depth of $991.1 \mathrm{~m}$ (Thorsteinsson and others, 1995b), with fabrics simulated in uniaxial compression with (b) static, (c) VPSC and (d) Taylor model for a vertical strain of 0.387 , corresponding to a depth of $990 \mathrm{~m}$. The centre of the diagrams indicates the in-situ vertical direction (a) and the direction of compression $(b-d)$.

measured GRIP fabric lies between the estimations of VPSC and Taylor models.

Let us now compare in-situ and simulated fabric concentrations for the whole $0-2800 \mathrm{~m}$ range of depth. In Figure 4, the average distribution of $c$-axes orientations is represented with a statistical parameter. $c$ axes are treated as unit vectors (denoted $\mathbf{c}^{g}$ ) within a hemisphere. The strength of orientation $R$ is proportional to the norm of the sum of all $\mathbf{c}^{g}$ vectors so that

$$
R \%=\left(2\left\|\sum_{g=1}^{N} \mathbf{c}^{g}\right\|-N\right) \frac{100}{N}
$$

where $N$ is the total number of grains in the polycrystal. The parameter $R$ is equal to $0 \%$ for a randomly oriented polycrystal and takes a maximal value of $100 \%$ when all $c$ axes are exactly parallel (Wallbrecher, 1978). From Figure 4, the difference between average fabric concentration predicted by static and VPSC models becomes significant only when the strength of orientation is higher than $80 \%$, i.e. for strongly pronounced fabrics. Both models reproduce very well the strength of orientation of the GRIP ice from the surface down to $650 \mathrm{~m}$ depth. From Figure 2a, this depth range exactly corresponds to the entire grain-growth zone. Below $650 \mathrm{~m}$, it clearly appears that the in-situ fabric evolution rate is lower than that predicted by the VPSC model. According to Castelnau and others (in press), this model also gives a good estimation of the fabric concentration for Vostok $(1720 \mathrm{~m})$ and Dome C (850 m) ice (Antarctica). These ice samples come from within the grain growth zone of the Antarctic ice sheet.

Below $2000 \mathrm{~m}$ depth, the strength of orientation of the

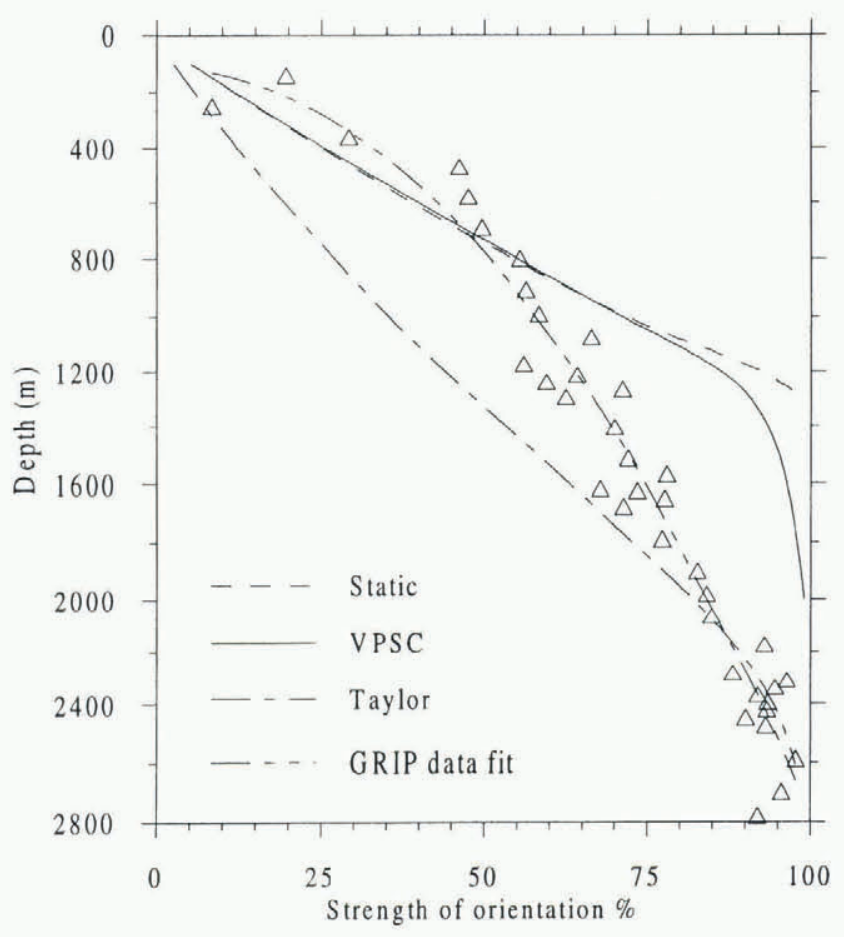

Fig. 4. Evolution of the strength of orientation with depth. Results of static, VPSC and Taylor models, compared to the measured GRIP data (triangles). The dash-dot-dot curve is a polynomial fit of these data. GRIP data are from Thorsteinsson and others (1995b).

GRIP core is best estimated using the Taylor bound model. However, the microscopic behaviour in ice polycrystals is very badly estimated using this model, which requires a large activation of non-basal systems. Thus, the Taylor model cannot be invoked for a realistic prediction of texture development. Features of simple shear (folds) are observed in the GRIP core below $2483 \mathrm{~m}$ depth (Alley and others, 1995b). But simulated and measured fabrics start to differ at only $650 \mathrm{~m}$. In an ice sheet, the horizontal shear stress may increase linearly with depth and with the surface slope. Simple shear can then hardly be the predominant deformation in the upper part of the GRIP core and cannot explain this discrepancy. The assumption made in the DansgaardJohnsen flow model on the variation of the vertical strain rate with depth could affect results only below $1625 \mathrm{~m}$ depth. For Holocene ice, the assumption of the constant vertical strain rate is assessed by direct measurements of the vertical strain. We therefore suggest that the slow fabric evolution below $650 \mathrm{~m}$, as compared with the modelled ones, is probably attributed to the effects of dynamic recrystallization.

The nucleation of new strain-free grains by sub-grain rotation is expected below $650 \mathrm{~m}$ depth in the GRIP core. According to Thorsteinsson and others (in press), subgrain boundaries in the GRIP ice were first observed at $380 \mathrm{~m}$ depth and appear frequently below $600 \mathrm{~m}$. The halt in grain growth below $650 \mathrm{~m}$ was attributed to this polygonization effect, which could also be the origin of the slower fabric-development rate below $650 \mathrm{~m}$. In the following section, we attempt to give a quantitative estimate of the effect of this recrystallization process. We will check whether this regime is compatible with the 
observed grain-size, vertical deformation rate, fabric evolution and grain shape, at least above a depth of $1625 \mathrm{~m}$.

Let us now assume that grain growth still occurs below $650 \mathrm{~m}$ depth but is counteracted by rotation recrystallization. According to Duval and Castelnau (1995), the GB migration rates within a rotation recrystallization regime and within a grain-growth regime are of the same order of magnitude. The variation of ice temperature from the icesheet surface down to $1800 \mathrm{~m}$ depth is less than $0.5^{\circ} \mathrm{C}$. Thus, ice temperature can be considered as being constant with depth. According to the DansgaardJohnsen model used to estimate the time-scale, a constant deformation rate down to $1750 \mathrm{~m}$ depth seems to be a good estimate of the in-situ flow. We can then consider, as a first approximation, that the grain-growth rate (defined as the growth rate of mean grain area measured on thin sections) is constant for all the Holocene ice and is equal to the value found by Thorsteinsson and others (in press) for depths between 0 and $650 \mathrm{~m}\left(K=3.8 \times 10^{3}\right.$ $\mathrm{mm}^{2}$ year $\left.{ }^{-1}\right)$. With this value, a constant grain-size between 650 and $1625 \mathrm{~m}$ depth is obtained if each grain is subdivided into two parts every 2000 years.

When rotation recrystallization occurs, the misorientation of sub-boundaries increases until the critical angle $2 \theta_{\mathrm{c}}$, which determines the transition between subboundary and grain boundary, is reached. According to Poirier (1985), the commonly adopted value for this critical angle is about $10-15^{\circ}$. As shown in Figure 5, an increasing misorientation produces changes in grain dimensions. The associated strain rate can be easily calculated and is found to be less than $4 \%$ of the vertical strain rate estimated at Summit $\left(\approx 10^{-4}\right.$ year $\left.{ }^{-1}\right)$. Polygonization effect does then not significantly contribute to the total deformation. This result is in accordance with the initial assumption of a constant strain rate down to a depth of $1750 \mathrm{~m}$.

We consider now a grain from the GRIP ice at $991.1 \mathrm{~m}$ depth, with a $c$ axis forming a $45^{\circ}$ angle to the vertical. The time needed by this $c$ axis to rotate towards $20^{\circ}$ from the vertical, as deformation proceeds, can be estimated with the VPSC model. The result is about 1800 years, a value which is of the same order as the 2000 years found above. This means that rotation recrystallization is not efficient enough to be the predominant process for fabric development, i.e. to produce fabrics completely different from those due to intracrystalline slip. However, the formation of new grains by the progressive misorientation of sub-boundaries should slow down the development of fabrics by slip. The discrepancy between the evolution of fabrics along the GRIP core and that given by the VPSC model (Fig. 4) can be explained by the occurrence of this physical process. Furthermore, a critical misorientation of $10-15^{\circ}$ is compatible with the most concentrated fabric found in the GRIP core (at $2586 \mathrm{~m}$ depth), which displays an aperture half-angle of $10-20^{\circ}$.

Finally, due to the vertical compression, initially spherical grains will be present after 2000 years, an aspect ratio (i.e. the ratio of horizontal size to vertical size) of 1.4 on average. Due to rotation recrystallization, the mean aspect ratio of grains deep in the GRIP core should then be around 1.2. This value compares well with

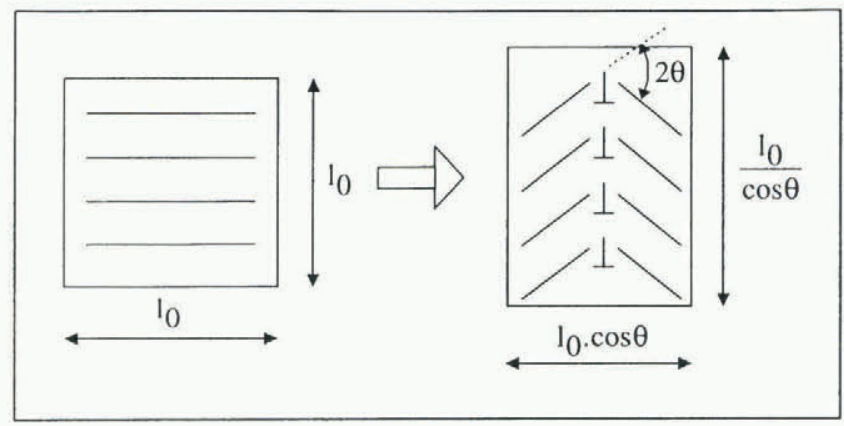

Fig. 5. Progressive misorientation of a sub-boundary and associated deformation.

that measured on thin sections between depths of 650 and $1625 \mathrm{~m}$, which is 1.32 on average (Fig. 2a).

This simple calculation is only a rough quantitative estimate of the influence of rotation recrystallization on fabric development. But it appears that this recrystallization regime is fully compatible with the textures and fabrics of the GRIP ices above $1625 \mathrm{~m}$ and could completely explain the constant grain-size and the slower fabric development below $650 \mathrm{~m}$. A similar conclusion, resulting from the observation of the distribution of $c$-axes orientation in the Byrd Station core, was given by Alley and others (1995a).

We have shown in this study that the VPSC model provides a good estimate of the $c$-axis fabric development within the grain-growth zone. Below $650 \mathrm{~m}$ depth, the influence of dynamic recrystallization is significant. A simple calculation shows that rotation recrystallization could completely explain discrepancies between model predictions and observations. The introduction within the VPSC polycrystal model of the effect of this recrystallization regime needs to be investigated to improve the simulation of fabric development in polar ices.

\section{ACKNOWLEDGEMENTS}

This work is a contribution to the Greenland Ice-core Project, carried out at Summit, central Greenland. Financial support was provided by the national funding bodies of Belgium, Denmark, France, Germany, Iceland, Italy, Switzerland, United Kingdom, under the auspices of the European Science Foundation. This work was also supported by the Programme National d'Études de la Dynamique du Climat, CNRS-France. We are very grateful to R. Lebensohn and C. Tomé for allowing us to use their self-consistent model, to S.J. Johnsen for having given us the latest estimation of the annual layer thickness ratio, to $\mathrm{N}$. Gundestrup for providing the latest temperature profile and to A. Salamatin for fruitful discussions. This paper is contribution No. 944 of the AlfredWegener-Institut.

\section{REFERENCES}

Alley, R. B. 1988. Fabrics in polar ice sheets: development and prediction. Science, $\mathbf{2 4 0} 4851), 493495$.

Alley, R. B. 1992. Flow-law hypotheses for ice-sheet modeling. $y$. Glaciol., 38 (129), 245-256.

Alley, R. B., J. H. Perepezko and C. R. Bentley. 1986. Grain growth in 
polar ice: II. Application. J. Glaciol., 32(112), 425-433.

Alley, R. B., A.J. Gow, S.J. Johnsen, J. Kipfstuhl, D. A. Meese and T. Thorsteinsson. 1995a. Comparison of deep ice cores. Nature, 373 6513), 393-394.

Alley, R. B., A.J. Gow and D. A. Meese. 1995b. Mapping $c$-axis fabrics to study physical processes in ice. f. Glaciol., 41(137), $197-203$.

Azuma, N. 1995. A flow law for anisotropic polycrystalline ice under uniaxial compressive deformation. Cold Reg. Sci. Technol., 23 2), 137-147.

Azuma, N. and A. Higashi. 1985. Formation processes of ice fabric pattern in ice sheets. Ann. Glaciol., 6, $130-134$

Budd, W.F. and T.H. Jacka, 1989. A review of ice rheology for ice sheet modelling. Cold Reg. Sci. Technol., 16 2), 107-144.

Castelnau, O. and P. Duval. 1994. Simulations of anisotropy and fabric development in polar ices. Ann. Glaciol., 20, 277-282.

Castelnau, O., P. Duval, R. A. Lebensohn and G. R. Canova. In press. Viscoplastic modelling of texture development in polycrystalline ice with a self-consistent approach: comparison with bound estimates. $\mathcal{J}$ Geophys. Res.

Dahl-Jensen, D., S.J. Johnsen, C. U. Hammer, H. B. Clausen and J. Jouzel. 1993. Past accumulation rates derived from observed annual lavers in the GRIP ice core from Summit, central Greenland. In Peltier, W.R., ed. Ice in the climate system. Berlin, etc., Springer-Verlag, 517-532. (NATO ASI Series I: Global Environmental Change 12.

Dansgaard, W. and S.J. Johnsen. 1969. A flow model and a time scale for the ice core from Camp Century, Greenland. J. Glaciol., 8 53), 215223.

Dansgaard, W. and 10 others. 1993. Evidence for general instability of past climate from a 250-kyr ice-core record. Nature, 364 6434), 218220.

Duval, P. and O. Castelnau. 1995. Dynamic recrystallization of ice in polar ice sheets. 7. Phys. (Paris), IV(5), Colloq. C3, 197-205. Supplément au 3.

Duval, P. and H. Le Gac. 1982. Mechanical behaviour of Antarctic ice. Ann. Glaciol., 3, 92-95.

Duval, P., M.F. Ashby and I. Anderman. 1983. Rate-controlling processes in the creep of polycrystalline ice. J. Phys. Chem., $87(21)$, 40664074.

Eshelby, J.D. 1957. The determination of the elastic field of an ellipsoidal inclusion, and related problems. Proc. R. Soc. London, Ser.A, 241. $376-396$

Fujita, S., M. Nakawo and S. Mae. 1987. Orientation of the 700-m Mizuho core and its strain history. Proceedings of the NIPR Symposium on Polar Meteorology and Glaciology 1, 122-131.

Fukuda, A., T. Hondoh and A. Higashi. 1987. Dislocation mechanisms of plastic deformation of ice. 7. Phys. (Paris). Ser. Colloq. C1, 48 , Supplément au 3, 163-173.

Gow, A.J. and T. Williamson. 1976. Rheological implications of the internal structure and crystal fabrics of the West Antarctic ice sheet as revealed by deep core drilling at Byrd Station. CRREL Rep. 76-35.

Gundestrup, N.S. and B. L. Hansen. 1984. Bore-hole survey at Dye 3, south Greenland. J. Glaciol., 30 (106), 282288.

Herron, S. L., C. C. Langway, Jr and K. A. Brugger. 1985. Ultrasonic velocities and crystalline anisotropy in the ice core from Dye 3 , Greenland. Geophys. Monogr. Am. Geophys, Union, 33, 23-31.

Hill, R. 1965. Continuum micro-mechanics of elastoplastic polycrystals. f. Mech. Phys. Solids, 13, 89101

Hutchinson, J. W. 1976. Bounds and self-consistent estimates for creep of polycrystalline materials. Proc. R. Soc. London, Ser. A, 348, 101-127.

Hutchinson, J. W. 1977. Creep and plasticity of hexagonal polycrystals as related to single crystal slip. Metall. Trans., A, 8 9), 1465-1469.

Jacka, T.H. 1984. The time and strain required for development of minimum strain rates in ice. Cold Reg. Sci. Technol., 8 3), 261-268.
Johnsen, S.J., D. Dahl-Jensen, W. Dansgaard and N.S. Gundestrup. 1995. Greenland paleotemperatures derived from GRIP borehole temperature and ice core isotope profiles. Tellus, Ser. B, 47 (5), 624 629.

Lebensohn, R.A. and C.N. Tomé. 1993. A self-consistent anisotropic approach for the simulation of plastic deformation and texture development of polycrystals: application to zirconium alloys. Acte Metall., 41, 2611-2624

L.ebensohn, R.A. and C. N. Tomé. 1994. A self-consistent viscoplastic model: prediction of rolling textures of anisotropic polycrystals Mater. Sci. Eng.. Ser. A, 175, 71-82.

Lipenkov, V.Y., N.I. Barkov, P. Duval and P. Pimienta. 1989 Crystalline texture of the $2083 \mathrm{~m}$ ice core at Vostok Station, Antarctica. 7. Glaciol., 35 (121), 392398.

Lliboutry, L. 1993. Anisotropic, transversely isotropic nonlinear viscosity of rock ice and rheological parameters inferred from homogenization. Int. 7. Plasticity, 9 5, 619632.

Lliboutry, L. and P. Duval. 1985. Various isotropic and anisotropic ices found in glaciers and polar ice caps and their corresponding rheologies. Annales Geophysicae, 3 2), 207-224.

Molinari, A., G. R. Canova and S. Ahzy. 1987. A self-consistent approach of the large deformation polycrystal viscoplasticity. Acte Metall., 35 (12), 2893-2994.

Paterson, W. S. B. 1991. Why ice-age ice is sometimes "soft". Cold Reg. Sci. Technol., 20 1), 75-98,

Pimienta, P. and P. Duval. 1989. Rheology of polar glacier ice (Abstract.) Ann. Glaciol., 12, 206-207.

Poirier, J. -P. 1985. Creep of crystals. Cambridge, Cambridge University Press.

Russell-Head, D.S. and W.F. Budd. 1979. Ice-sheet flow properties derived from bore-hole shear measurements combined with ice-core studies. J. Glaciol., 24 90$)$, $117-130$.

Sachs, G. 1928. Zur Ableitung einer Fliessbedingung. Z. des Vererins Deutscher Ingenienre, 72 8), 734-736.

Shoji, H. and C. C. Langway, Jr. 1988. Flow-law parameters of the Dye 3, Greenland, deep ice core. Ann. Glaciol., 10, 146-150.

Steinemann, S, 1954. Flow and recrystallization of ice. International Association of Scientific Hydrology Publication 39. (General Assembly of Rome 1954 - Snow and $I c e), 449462$.

Taylor, G. I. 1938. Plastic strain in metals. 7. Inst. Met., 62, 307-324.

Thorsteinsson, T., J. Kipfstuhl, H. Eicken, S. J. Johnsen and K. Fuhrer. 1995. Crystal size variations in Eemian-age ice from the GRIP ice core, central Greenland. Earth Planet. Sci. Lett., 131(3-4), 381-394.

Thorsteinsson, T., J. Kipfstuhl and H. Miller. In press. Texture and fabrics in the GRIP ice core. 7. Geophys. Res.

Tomé, C. N., H.-R. Wenk. G. R. Canova and U.F. Kocks. 1991. Simulations of texture development in calcite: comparison of polycrystal plasticity theories. 7. Geophys. Res., 96 B7), 11,86511,875 .

Van der Veen, C.J. and I. M. Whillans. 1994. Development of fabric in ice. Cold Reg. Sci. Technol., 22 2), 171-195.

Wallbrecher, E. 1978. Ein Clusterverfahren zur Richtungsstatistischen Analyse tektonischer Daten. Geol. Rundsch., 67, 840857.

Wenk. H. R., T. Takeshita, P. van Houtte and F. Wagner. 1986. Plastic anisotropy and texture development in calcite polvcrystals. 7 Geophys. Res., 91 B3), 3861-3869

Wenk, H.-R., G. R. Canova, A. Molinari and H. Mecking. 1989a. Texture development in halite: comparison of Taylor model and selfconsistent theory. Acta Metall.. 37 7), 2017-2029.

Wenk, H.-R., G. Canova, A. Molinari and U.F. Kocks. 1989b. Viscoplastic modeling of texture development in quartzite. 7 . Geophys. Res., 94 (B12), 17,895-17,906. 